ISSN 2088-5415 (print)

ISSN 2355-5777 (Online)

DOI 10.22146/kawistara.27879

Https://jurnal.ugm.ac.id/kawistara

KAWISTARA

VOLUME 7

No. 3, 22 Desember 2017

Halaman 207-314

\title{
PAKET WISATA EDUKASI SUBAK UPAYA MENJAGA KEBERLANJUTAN POTENSI PERTANIAN DAN PARIWISATA BERBASIS BUDAYA DI BALI
}

\author{
Ni Luh Ramaswati Purnawan \\ Fakultas Ilmu Sosial dan Ilmu Politik, Universitas Udayana \\ Email: ramaswati.purnawan@gmail.com \\ I Ketut Sardiana \\ Fakultas Pertanian, Universitas Udayana
}

\begin{abstract}
Tourism and agriculture are leading sectors of development in Bali Province. Before Bali's economy relies heavily on tourism sector, agriculture was a major driver of economic growth. However, with so many challenges of land adjustment and use, and the increase tendency of agricultural land conversion into non-agricultural purpose, the growth of the agricultural sector gradually decreased. Declining of agriculture domain might cause a challenge for Bali because agriculture is not just an activity of land cultivation, but it has related more as spirit or the essential substances of Balinese cultural identity. One of the agricultural universal icons is the Subak system, which has named as world cultural heritage by UNESCO in 2012. Thus, to ensure the sustainability of the agricultural and tourism in Bali, the effort to combine both fields through development of Subak educational tourism becomes relevant. This idea is based on the perspectives that agricultural and tourism areas are interrelated systems. Tourism in Bali is counting on how Bali can preserve its natural and cultural attractions, this include the agrarian culture and lifestyle. The emergence of knowledge-based society, that encourage travellers to be actively involved and participate to fulfill their desire of learning and understanding others culture, has greatly contributed to development of this special interest tourism. Study indicated that Subak educational tourism can be applied toward sustainability as it incorporated the aspect of natural and socio-cultural conservation and could offer economic benefits for the well-being of the local community.
\end{abstract}

Keywords: Agricultur; Cultural identit; Subak educational tourism; Sustainability; Tourism

\begin{abstract}
ABSTRAK
Sektor pariwisata dan pertanian merupakan sektor unggulan pembangunan di Provinsi Bali. Sebelum sektor pariwisata mendominasi perekonomian Bali, pertanian merupakan penggerak utama kegiatan perekonomian. Namun, dengan adanya tantangan penyesuaian dan penggunaan lahan, serta kecenderungan peningkatan alih fungsi lahan pertanian ke lahan bukan pertanian, maka pertumbuhan sektor pertanian mengalami penurunan. Penurunan sektor pertanian ini merupakan tantangan tersendiri karena pertanian bukan sekedar aktivitas bercocok tanam, namun telah menjadi roh sekaligus esensi penting dari identitas kebudayaan Bali. Untuk menjamin keberlanjutan sektor pertanian, maka upaya menggabungkan sektor ini dengan industri pariwisata melalui pengembangan wisata edukasi subak menjadi relevan. Hal ini didasarkan pada perspektif, bahwa sektor pertanian dan pariwisata adalah sistem yang saling berkaitan. Pariwisata di Bali sangat bergantung pada bagaimana Bali dapat melestarikan atraksi alam dan budayanya, termasuk budaya agraris. Munculnya knowledge-based society yang mendorong meningkatnya keinginan wisatawan untuk aktif terlibat dan berpartisipasi
\end{abstract}


untuk memenuhi kebutuhan akan atraksi wisata yang memiliki komponen pendidikan dan pembelajaran turut berkontribusi dalam perkembangan jenis wisata minat khusus ini. Studi menunjukkan bahwa wisata edukasi subak merupakan langkah yang dapat dilakukan untuk mewujudkan adanya keberlanjutan (sustainability), karena mengandung aspek pelestarian lingkungan alam, sosial budaya dan ekonomi bagi masyarakat setempat.

Kata kunci: Identitas budaya; Pariwisat; Pertanian; Keberlanjutan; Wisata Edukasi Subak.

\section{PENGANTAR}

Sektor pariwisata dan pertanian merupakan sektor unggulan pembangunan di Provinsi Bali. Saat ini, pariwisata merupakan penggerak utama perekonomian di Bali. Sektor ini memberikan peningkatan pendapatan bagi Bali, yaitu sebesar 22,8\%, yang terutama bersumber dari penyediaan akomodasi dan makan minum yang berkaitan dengan pariwisata. Pendapatan terbesar kedua, sekitar $14,74 \%$ diperoleh dari sektor pertanian, kehutanan dan perikanan (BPS, 2017).

Sebelum sektor pariwisata mendominasi perekonomian Bali, pertanian merupakan penggerak utama kegiatan perekonomian (Provinsi Bali, 2015). Sebagian besar masyarakat Bali bercorak produksi sebagai petani dengan pola pertanian tradisional yang bergerak di sub-sektor pertanian tanaman pangan, seperti padi-padian, palawija, dan hortikultura.

Dari total luas wilayah Provinsi Bali yang mencapai 5.636,66 $\mathrm{km}^{2}$, jumlah lahan pertanian di Bali mencapai 353.491 hektar yang terdiri dari lahan sawah seluas 79.526 hektar dan lahan bukan sawah seluas 273.965 hektar. Pemanfaatan lahan sawah tertinggi tercatat di wilayah Kabupaten Tabanan, dengan luas lahan mencapai 21.452 hektar. Akan tetapi, dengan adanya tantangan penyesuaian dan penggunaan lahan, serta kecenderungan peningkatan alih fungsi lahan pertanian ke lahan bukan pertanian, maka pertumbuhan sektor pertanian mengalami penurunan. Data tahun 2015 menunjukkan bahwa sektor pertanian, kehutanan, dan perikanan mengalami pertumbuhan terendah jika dibandingkan dengan sektor lainnya (BPS, 2017).

Penurunan sektor pertanian ini merupakan tantangan tersendiri karena pertanian bukan sekedar bercocok tanam, tetapi telah menjadi roh sekaligus esensi penting dari identitas kebudayaan Bali. Hal ini didasarkan pada penemuan peninggalan-peninggalan batu dan logam sejak 200-100 sebelum Masehi, artinya bahwa ini menunjukkan kepercayaan yang erat hubungannya dengan kesuburan untuk kesejahteraan dalam hidup bersama, melalui aktivitas bercocok tanam sebagai aktivitas utama.

Pada masa itu pula, telah dikenal pembudidayaan padi di sawah beririgasi yang teratur karena diatur secara adil dan merata oleh perkumpulan pemakai air sawah (sekaa subak). Sistem subak dikenal melalui teks prasasti pada abad ke-11 dan ke-12, yaitu pada Prasasti Pandak Badung bertahun 1071 Masehi menyebut kesuwakan talaga; Prasasti Klungkung A,B,C bertahun 1072 Masehi menyebut istilah kesubakan rawas dan sungai (Yeh) Hee; Prasasti Bugbug dan Prasasti Buahan D, keduanya bertahun Masehi 1181 menyebut kasewakan bunglunan, suwak, kasewakan. Akan tetapi, dalam bukti-bukti arkeologis dan sejarah bahwa Subak di Gelgel sudah ada jauh sebelum tersurat dalam prasasti yang disebut di atas (Wirawan, 2011).

Dengan memperhatikan hal tersebut di atas, dapat dikatakan bahwa aktivitas bercocok tanam dan sistem subak telah menjadi way of life masyarakat yang berlangsung lama dan dilakukan secara turun temurun. Hal ini kemudian menyebabkan pertanian dan aktivitas bercocok tanam dikatakan sebagai bagian dari kebudayaan masyarakat di Bali.

Subak merupakan lembaga tradisional perkumpulan irigasi atau pemakaian dan pembagian air sawah dan masih tetap terjaga hingga kini. Fungsi utama Subak, selain untuk mengatur distribusi dan pemeliharaan air irigasi, pengerahan sumber daya, termasuk juga berfungsi sebagai conflict solution jika ada permasalahan dan penyelenggara ritual terkait aktivitas pertanian dan bercocok tanam. Oleh karena itu, Subak dinyatakan sebagai 
masyarakat hukum adat yang memiliki fungsi sosio-agraris-religius (Windia, et al, 2005).

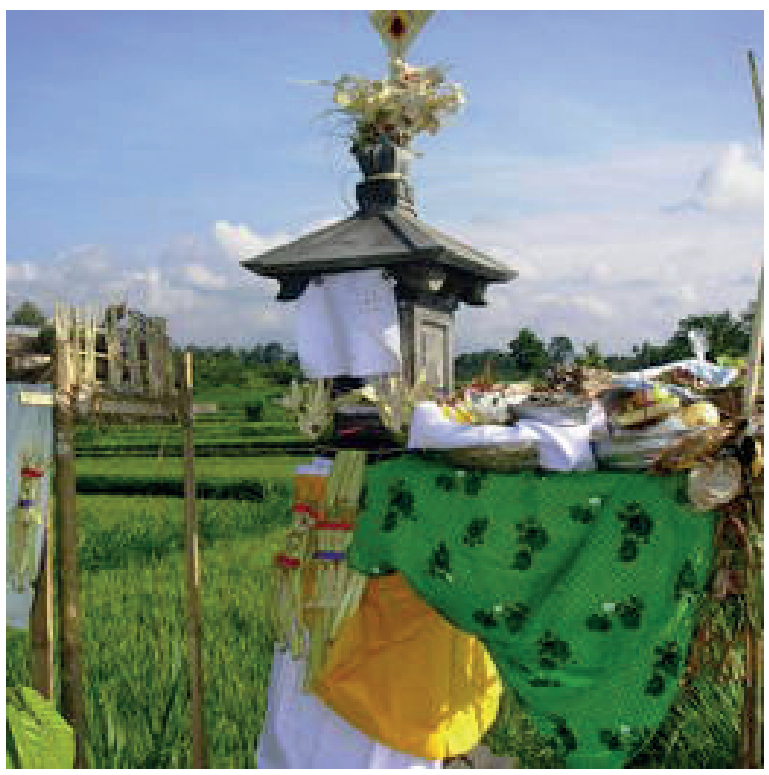

Gambar 1. Ritual di Pura Subak Sumber : UNESCO, 2012

Melihat keunikan sistem subak yang merupakan bagian dari kebudayaan Bali dan sebagai upaya pelestarian subak dan pertumbuhan sektor pertanian, maka langkah menggabungkan kegiatan budaya, pertanian, dan subak dengan kegiatan pariwisata melalui wisata edukasi subak menjadi penting. Hal ini berdasarkan perspektif bahwa sektor pertanian dan pariwisata adalah sistem yang saling terkait. Pariwisata di Bali sangat bergantung pada bagaimana Bali dapat melestarikan atraksi alam dan budayanya, termasuk budaya agraris. Dengan mempertahankan keberadaan sistem pertanian dan subak di Bali, berarti membantu melestarikan budaya sebagai pilar pengembangan pariwisata di Bali.

Relevansi pengembangan wisata edukasi berbasis Subak sangat terkait perubahan tren berwisata dan pendidikan. Meningkatnya level pendidikan dalam masyarakat menimbulkan dampak terhadap trend berwisata. Knowledgebased society mendorong meningkatnya keinginan wisatawan untuk secara aktif terlibat dan berpartisipasi - dikenal dengan istilah active vacation atau leisure-education hybrid', yang mengacu kepada kebutuhan akan atraksi wisata yang memiliki komponen pendidikan dan pembelajaran.
Beberapa hal yang memberi indikasi bahwa wisata edukasi Subak memiliki potensi untuk dikembangkan, di antaranya: pertama, The natural and cultural heritage, diversities and living cultures are major tourism attractions (ICOMOS, 2002); kedua, sistem irigasi Subak dan kawasan Jatiluih, yang terkenal sebagai kawasan pertanian, telah ditetapkan sebagai warisan budaya dunia oleh UNESCO sejak tahun 2012. Hal ini menunjukkan bahwa sistem dan aktivitas masyarakat di Bali yang sudah dilakukan secara turun temurun, dalam menjaga keberlangsungan ekologi dan harmonisasi hubungan antarmanusia dan dengan Sang Pencipta, memiliki nilainilai budaya universal. Hal ini berpotensi untuk dapat menarik lebih banyak kunjungan wisatawan untuk mengenal dan mempelajari kebudayaan Bali.

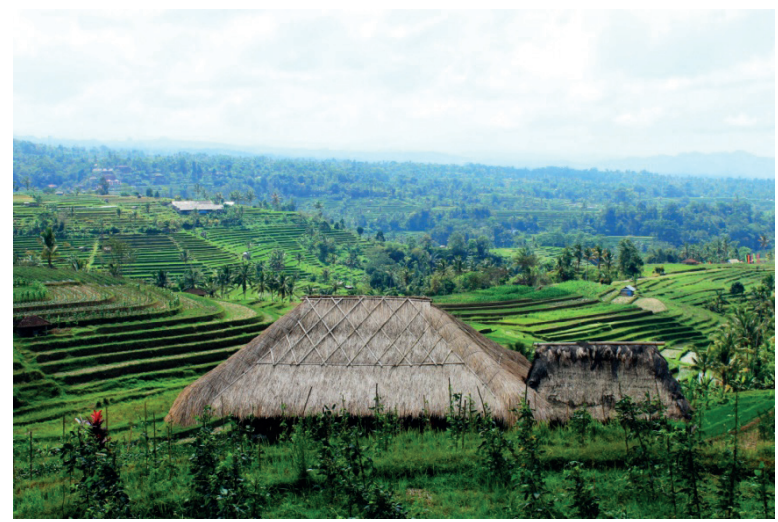

Gambar 2. Kawasan Pertanian di Desa Jatiluih, Kabupaten Tabanan, Bali

Dokumentasi: Ramaswati Purnawan

Tulisan ini disusun sebagai upaya memadukan potensi budaya, pertanian, dan pariwisata secara terintegrasi melalui pengembangan paket wisata edukasi Subak. Lokasi studi berada di Desa Jatiluih, Kecamatan Penebel, Kabupaten Tabanan. Studi ini dilakukan pada Kelompok Umaduwi, Subak Jatiluih yang beranggotakan 15 orang petani. Informasi primer dalam tulisan ini diperoleh melalui wawancara dan observasi partisipatoris. Wawancara dilakukan untuk mendapatkan informasi mengenai aktivitas subak dan upaya pengembangan wisata edukasi Subak, yang diarahkan pada pembuatan paket wisata. Observasi partisipatori juga dilakukan 
untuk mengamati berbagai aktivitas yang dapat dikembangkan sebagai atraksi dalam pembuatan paket wisata edukasi Subak. Untuk melengkapi informasi dalam tulisan ini, data sekunder diperoleh melalui bacaan, hasil penelitian, arsip dan dokumen yang terkait budaya pertanian, sistem subak, pariwisata budaya, dan wisata edukasi. Data yang dperoleh kemudian dianalisis, dengan terlebih dahulu menyusun transkrip dan catatan observasi, selanjutnya data kemudian disajikan secara deskriptif.

\section{PEMBAHASAN}

\section{Pariwisata Budaya sebagai Komitmen Pengembangan Kepariwisataan di Bali}

Pariwisata budaya merupakan pasar pariwisata terbesar dan memiliki peluang sangat besar untuk berkembang dengan pesat. Hal ini dapat dilihat dengan semakin banyaknya unsur budaya dan industri kreatif yang digunakan untuk mempromosikan dan meningkatkan advantages competitveness dan attractiveness dari sebuah destinasi (OECD, 2015). Catatan WTO menyebutkan sekitar 37\% kepariwisataan internasional merupakan kegiatan wisata budaya, dan memperkirakan bahwa wisata budaya akan mengalami tingkat pertumbuhan 15\% setiap tahunnya (Richards, 2003).

McIntosh and Goeldner (1986; dalam Richard, 2003) menyatakan bahwa pariwisata budaya adalah semua aspek tentang perjalanan wisata di mana pelancong memiliki kesempatan untuk mempelajari sejarah (history) dan warisan budaya (heritage) daerah lain atau tentang cara hidup (contemporary ways of life) dan pola pikir (thought) budaya lain. ATLAS kemudian menyatakan definisi pariwisata budaya sebagai perjalanan pelancong untuk menikmati atraksi budaya yang berada jauh dari tempat mereka tinggal sehari-hari, dengan maksud untuk memperoleh informasi dan pengalaman baru untuk memuaskan kebutuhan akan kegiatan yang berkaitan dengan kebudayaan.

Dalam definisi yang lebih luas, World Tourism Organisation (WTO) menyatakan bahwa aktivitas wisata budaya termasuk semua bentuk perjalanan seseorang disebabkan adanya kebutuhan manusia untuk melihat keberagaman (diversity), yang mendorong individu untuk memiliki kecenderungan meningkatkan pemahaman budaya mereka dan budaya lain serta selalu berupaya untuk menambah pengetahuan, pengalaman, dan bertemu orang-orang baru.

Konsumsi budaya yang dimaksud di antaranya..."what people think (attitudes, beliefs, ideas, and values), what people do (normative behaviour patterns, or way of life) and what people make (artworks, artefacts, cultural products) (Littrell, 1997; dalam Richards, 2003).

Dari beberapa definisi di atas, pariwisata budaya adalah penggunaan potensi budaya dalam kegiatan pariwisata. Budaya yang dimaksud terdiri dari proses (berupa ide-ide atau gagasan dan 'way of life') dan produk dari proses tersebut (di antanya bangunan, artefak, kesenian, kebiasaan, dan lain-lain) sehingga karakteristik pariwisata budaya berupa aktivitas pariwisata yang tidak saja menyangkut konsumsi dari produk budaya masa lalu - seperti mengunjungi tempat bersejarah atau museum saja, tetapi juga termasuk 'mengkonsumsi 'way of life' dari suatu masyarakat atau daerah yang dikunjungi. Kedua aktivitas budaya tersebut kemudian akan memberi kesempatan kepada pelancong untuk memperoleh pengetahuan dan pengalaman baru, yang mungkin berbeda dari kehidupan mereka sehari-hari. Selain itu, pariwisata budaya lebih menitikberatkan pada proses pembelajaran (learning aspect), di mana pelancong yang berminat menjalani pariwisata budaya termotivasi untuk mempelajari produk dan proses dari budaya lain yang berbeda dari budaya mereka sendiri.

Pemerintah Provinsi Bali telah berkomitmen untuk mengembangkan pariwisata budaya sebagai ikon kepariwisataan daerah. Hal ini termuat dalam Peraturan Daerah Propinsi daerah Tingkat I Bali No.3 Th 1974, sebagaimana diubah menjadi Perda 3 Tahun 1991 Tentang Pariwisata Budaya, dan diubah menjadi Peraturan Daerah Provinsi Bali Nomor 2 Tahun 2012 Tentang Kepariwisataan Budaya Bali. 


\section{Subak - Organisasi Tradisional Pengelolaan Irigasi Lahan Pertanian}

Subak merupakan organisasi yang anggotanya adalah para petani, yang memiliki aktivitas utama dalam pengelolaan penggunaan air bagi anggotanya secara proporsional. Hingga saat ini terdapat 2729 pengairan, yang terdiri dari 1441 subak lahan sawah dan 1118 subak perkebunan. Subak selain merupakan aktivitas pertanian - yang berfungsi untuk (1) mengatur pembagian air bagi para anggotanya agar masing-masing memperoleh air dengan seadil-adilnya dengan tujuan mensejahterakan anggotanya; (2) wajib memelihara sumbersumber air; (3) mengatur jenis padi yang ditanam, menetapkan waktu penyiapan lahan, penaburan benih dan tanam - juga merupakan aktivitas sosial karena melibatkan kerjasama, gotong royong antarpetani tidak saja dengan sesama anggota dalam satu kelompok, termasuk juga kerjasama antarsubak, misalnya dalam sistem meminjam air irigasi.

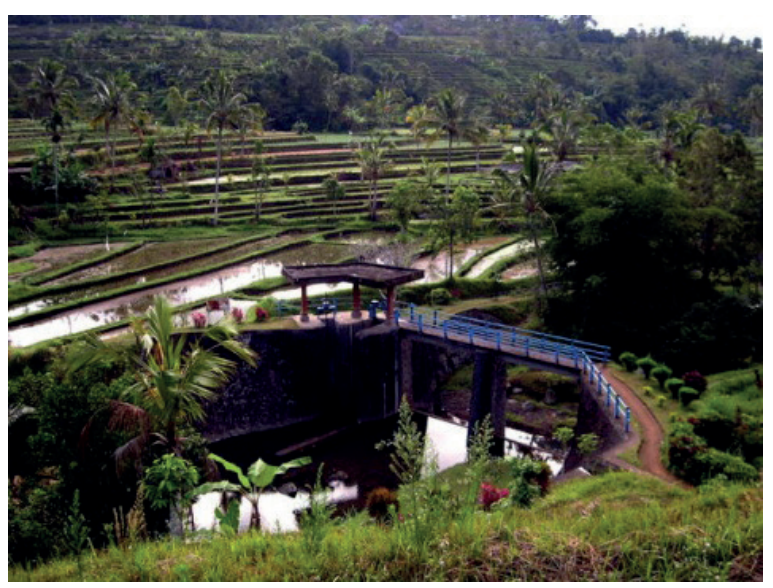

Gambar 3. Sistem Irigasi Subak Sumber : UNESCO, 2012

Organisasi subak ini telah memiliki kelengkapan organisasi antara lain: peraturan atau disebut awig-awig yang mengikat para anggota dalam melakukan hak, kewajiban termasuk sanksi apabila melanggar dari aturan yang disepakati; pengurus atau pekaseh, yang bertugas mengatur penggunaan air serta koordinasi dengan pimpinan lembaga lain dalam lingkungannya, seperti pimpinan desa adat, desa dinas, lembaga pemerintahan dan lain-lain. Selain itu, Subak juga merupakan suatu entitas religius, dengan memiliki Pura Bedugul, yang dipandang sebagai mekanisme kontrol terhadap pengelolaan air irigasi dan secara rutin menyelenggarakan upacara keagamaan (Sutawan dkk, 1989; dalam Windia dkk, 2005). Upacara yang dilakukan berkaitan dengan kesuburan untuk peningkatan kesejahteraan hidup masyarakat.

\section{Wisata Edukasi}

Wisata edukasi termasuk dalam kategori alternative tourism atau bagian dari special interest tourism. Berawal dari kekuatiran akan meningkatnya dampak negatif yang dirasakan akibat perkembangan mass tourism dan upaya pencarian destinasi wisata baru, mendorong berkembangnya keinginan akan adanya jenis wisata alternatif. Sejak tahun 1980-an, pariwisata telah menjadi lebih specialized dan segmented, yang kemudian memunculkan beberapa jenis niche market sebagai alternatif seperti rural tourism, ecotourism, adventure tourism, dan lain-lain. Selain itu, wisata edukasi juga berkembang sebagai akibat adanya perubahan.".. from an industrial to knowledgebased or learning economy and society with an increasing emphasis on extending learning beyond initial schooling" (OECD, 2011). Wisata edukasi merefleksikan tren berwisata yang menekankan pada upaya pelestarian, pemenuhan kebutuhan akan ilmu, dan pengetahuan serta kesadaran terhadap lingkungan sekitar. Yang dimaksud wisata edukasi (educational tourism) sebagai berikut:

\footnotetext{
"Tourist activity undertaken by those who are undertaking an overnight vacation and those who are undertaking an excursion for whom education and learning is a primary or secondary part of their trip. This can be include general educational tourism and adult study tours, international and domestic university and school students' travel, including language school, school excursionss and exchange programmes. Educational tourism can be independently or formally organised and can be undertaken in a variety of natural or human-made setting" (Rithcie et al, 2003).
} 
Sesungguhnya wisata edukasi bukanlah atraksi baru karena literatur menunjukkan bahwa wisata edukasi telah ada mulai abad ke-17 dan menjadi tren sekitar abad ke19, diawali dengan tumbuhnya Grand Tour yang dilakukan oleh para kaum aristrokrat dan terpelajar di Inggris sebagai bagian dari program pendidikan mereka. Perjalanan yang dapat berlangsung hingga beberapa tahun ini bertujuan untuk memperoleh pendidikan dan pengetahuan, dengan melakukan kunjungan ke negara Eropa, seperti Perancis, Swiss, dan Jerman. Kegiatan study tour ini meliputi belajar bahasa asing, budaya setempat (seperti menari), termasuk pula perjalanan ke universitas.

Menurut Ritchie, Carr dan Cooper (2003), wisata edukasi dapat dibedakan menjadi dua kategori, yaitu (1) 'tourism first', mengacu kepada wisatawan yag tertarik untuk mengetahui dan belajar pada saat melakukan tour, cenderung melakukan guided tour dan interpretative (general interest in learning while travelling); dan (2) 'education first', yakni wisatawan telah merencanakan untuk mengikuti pendidikan dan pelatihan (purposeful learning and travel). Maka dari itu, segmentasi wisata edukasi dinyatakan sebagai berikut: (1) General travel for education (or edu-tourism) and adult or seniors' educational tourism, where some form of education or learning is an important (and often motivating) part of the tourist experience; (2) University/college students' and schools' tourism (language schools, school excursions and exchange programmes), whereby tourist experiences may be secondary to the educational aspect or intentions and may be considered 'education first' educational tourism experiences or products.

Jenis wisata ini dapat berupa perjalanan domestik maupun internasional yang diorganisir oleh sekolah/lembaga pendidikan (school/field trips). School tourism dapat dibagi menjadi dua jenis, yaitu (a) curriculum-based trip merupakan wisata pendidikan yang dilakukan berkaitan secara langsung dengan mata pelajaran yang diterima dikelas, sesuai dengan kurikulum pembelajaran; b) extra-curricular excursion merupakan perjalanan yang tidak berhubungan dengan kurikulum pembelajaran dan tidak berkaitan dengan kelas atau disiplin ilmu yang diikuti.

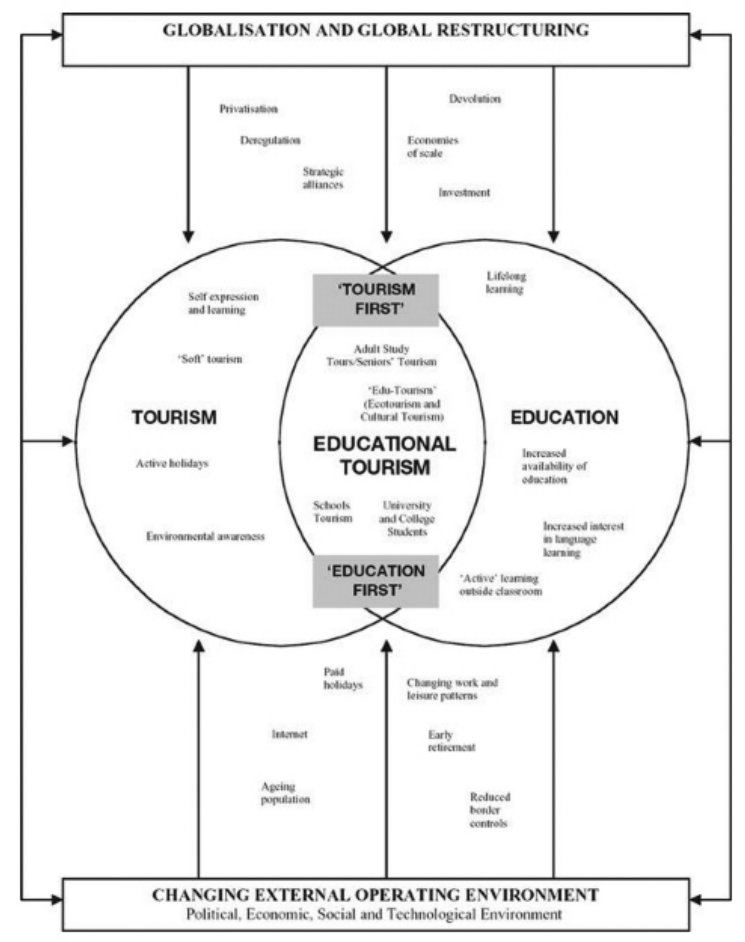

Gambar 4. Conceptualising educational tourism : a segmentation approach

Sumber: Ritchie, Carr, and Cooper, 2003

\section{Wisata Edukasi Subak: Alternatif Pengembangan Pariwisata berbasis Pertanian dan Budaya di Bali}

Wisata edukasi tidak hanya untuk memuaskan keingintahuan akan budaya dari bangsa lain - seperti bahasa asing, kesenian, kepedulian akan kelestarian lingkungan alam dan biodiversity lokal, memperdalam pengetahuan tentang budaya dan tempat bersejarah bagi suatu bangsa - namun lebih menekankan pada proses pembelajaran yang dirancang/ organized learning.

Wisata Edukasi Subak dapat memfasilitas keinginan wisatawan untuk lebih mengetahui dan menginginkan adanya proses pembelajaran (learning experience). Potensi penggunaan lahan pertanian sebagai satu atraksi wisata sangat tinggi. Penggunaan kawasan pertanian sebagai atraksi wisata dikenal dengan berbagai sebutan, di antaranya agritourism; agrotourism; farm tourism, farm-based tourism, dan vacation 
farm (Weaver and Fennell 1997; dalam Phillip dkk, 2010).

Dalam mengembangkan wisata edukasi subak, tipologi agrowisata yang disusun oleh Phillip dkk, 2010, yang mengintegrasikan antara produk dan aktivitas yang termasuk dalam kategori agrowisata, dapat digunakan. Menurut Phillip et al, kegiatan agrowisata dapat dikelompokkan berdasarkan pada tiga aspek, yakni: apakah aktivitas tersebut memanfaatkan lahan pertanian (working farm); adakah keikutsertaan wisatawan dalam aktivitas pertanian (contact between the tourist and agrociltural activity); serta tingkat autentisitas (degree of authenticity) pengalaman yang akan diperoleh wisatawan saat melakukan aktivitas di sawah/lahan pertanian. Tipologi tersebut antara lain:

- No Working Farm agritourism, mengacu kepada partisipasi wisatawan secara pasif terhadap aktivitas agrowisata, ditandai dengan tidak adanya aktivitas dilakukan dalam lahan pertanian (no working farm). Kegiatan termasuk mengunjungi farm heritage or imagery (dapat berupa kunjungan ke museum yang memiliki kaitan dengan produk dan praktek pertanian di masa lalu), atau sekedar beraktivitas/berjalanjalan melewati areal pertanian dalam perjalanan menuju aktivitas utama wisata.

- Working Farm Passive Contact agritourism. Tipologi ini menggunakan lahan pertanian untuk konteks berwisata, namun aktivitas wisatawan bersifat pasif, tidak adanya kontak dengan kegiatan pertanian yang berlangsung di lahan tersebut.

- Working Farm Indirect Contact Agritourism, mengacu pada tipologi yang mulai memadukan aktivitas dalam lahan pertanian dengan produk wisata, walaupun interaksi dengan komoditas pertanian masih bersifat tidak langsung.

- Working Farm, Direct Contact, Staged Agrotourism. Dalam tipologi ini aktivitas pertanian yang dilakukan oleh wisatawan bukan merupakan aktivitas authentic, namun telah dikemas khusus sebagai produk wisata (staged/purposefully put on), dengan pertimbangan kesehatan dan keamanan. Aktivitas kategori ini termasuk farming demonstration.

- Working Farm, Direct Contact, Authentic Agritourism. Perbedaan tipologi ini dengan tipologi sebelumnya adalah wisatawan mendapatkan pengalaman authentic dalam melakukan aktivitas agrowisata, pengalaman terlibat langsung, first-hand, dalam aktivitas pertanian secara natural, seperti ikut menanam atau memetik hasil pertanian (pick-your-own). Contoh lainnya berupa keikutsertaan wisatawan sebagai pekerja dalam kegiatan organic farming, sebagai kompensasi atas biaya tempat tinggal/ akomodasi dan/atau makanan.

Berdasarkan tipologi berikut, maka kegiatan wisata edukasi Subak dapat dilakukan berdasarkan tipologi keempat dan kelima, dimana proses pembelajaran dilakukan secara langsung di lahan pertanian, dengan pilihan derajat aktivitas berupa aktivitas yang dikemas secara khusus bagi wisatawan (staged), maupun bersifat authentic. Alternatif lainnya, yakni aktivitas pembelajaran dapat pula dikombinasikan dengan tipologi pertama, yang tidak dilakukan dilahan pertanian secara langsung, namun bertujuan untuk memberi pengenalan aktivitas, alat dan produk pertanian berupa kunjungan ke museum subak misalnya.

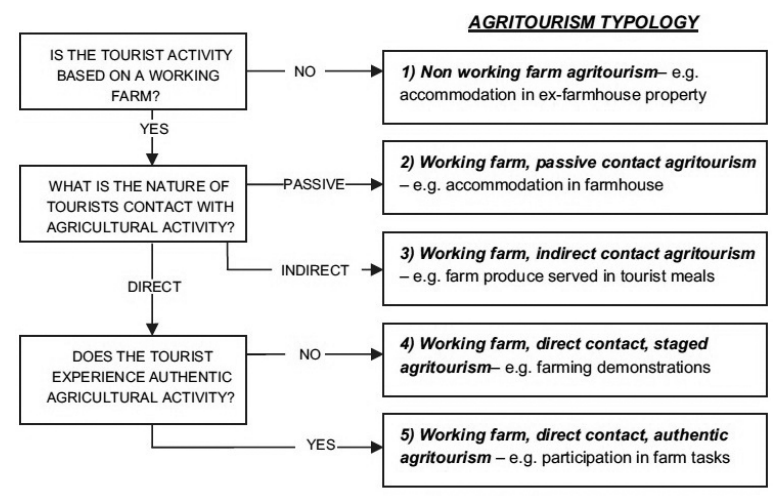

Gambar 5. Typology of Agritourism Sumber : Phillip et al. (2010)

Berdasarkan hal tersebut di atas, implementasi paket wisata edukasi subak dapat disusun sebagai berikut. Pertama, Sight seeing yaitu aktivitas ini sesuai dengan tipologi yang mengacu kepada partisipasi wisatawan 
secara pasif terhadap aktivitas agrowisata. Kegiatan ini memanfaatkan potensi visual berupa panorama sawah bertingkat yang didukung dengan suasana yang sejuk dan alami. Aktivitas ini sangat memungkinkan dilakukan karena daerah Jatiluih memiliki hamparan sawah bertingkat yang menarik untuk diabadikan. Fasilitas/sarana pendukung yang diperlukan seperti tempat pemberhentian (wiew point), yang dapat dilengkapi dengan fasilitas penunjang pariwisata seperti rumah makan atau kedai minum kopi cukup tersedia.

Kedua, Kegiatan yang terkait dengan Subak dan edukasi pertanian. Pada dasarnya kegiatan ini merupakan inti dari wisata edukasi subak, yang dapat digunakan untuk memberikan pengetahuan dan pemahaman subak sebagai kepada wisatawan. Kegiatan yang dilakukan dapat dibedakan berdasarkan penekanan edukasi, apakah education first atau tourism first. Untuk itu, beberapa alternatif aktivitas yang dilakukan dapat berupa salah satu atau gabungan dari aktivitas berikut :

a. Pembelajaran di dalam kelas (Classroom activities)

Aktivitas pembelajaran ini sesuai untuk tipe wisatawan yang lebih menekankan pada aspek education first (general edutourism atau school/university college tourism), yang berkunjung dalam kaitannya dengan kurikulum pendidikan atau extra-curriculer excursion di negara asal. Aktivitas ini dapat dilakukan di dalam kelas atau ruangan lainnya seperti (Museum Subak) yang di dalamnya dipajang gambar-gambar tentang proses pertanian dan beberapa alat pertanian tradisional. Wisatawan diberikan penjelasan/pelajaran tentang subak dan proses/aktivitas pertanian lahan basah. Penjelasan ini dapat menggunakan alat bantu berupa gambar, film/video dokumentasi, dan visualisasi alat-alat pertanian.

\section{b. On Farm Activities}

Aktivitas ini dapat dikombinasikan dengan in-class activities, atau berdiri sendiri. Pada dasarnya kegiatan dapat berupa direct atau indirect kontak dengan aktivitas pertanian.
Direct contact dapat berupa menikmati langsung aktivitas pertanian berupa praktek pengolahan lahan/membajak secara tradisional (metekap), mebubu (menangkap belut), praktek pengolahan hasil dari padi menjadi beras (menumbuk padi), pengolahan kopi dan penganan tradisional, dan bahkan praktik cooking, yaitu memasak beras secara tradisional atau olahan lain hasil produk pertanian khas setempat. Kegiatan ini dapat diakhiri dengan makan siang yang bahannya diperoleh dari lahan pertanian setempat seperti nasi beras merah (organik), belut goreng/pepes, dan sate keong. Selain itu aktivitas yang berkaitan dengan penunjang kegiatan pertanian seperti pemeliharaan ternak untuk mengolah lahan dan pengolahan kotoran ternak sebagai sumber pupuk dan biogas dapat pula dikembangkan. Sifat kegiatan ini dapat berupa aktivitas alami kelompok subak maupun aktivitas yang disetting layaknya seperti aktivitas seharihari (staged). Aktivitas indirect contact dapat dilakukan seperti kunjungan pada on-site processing kopi.

Aktivitas direct contact dan staged agrotourism ini sesuai dengan tren experience economy di mana pengalaman (experience) merupakan sumber nilai ekonomi terbaru setelah komoditas, barang atau jasa (commodity, good or service). Pengalaman dipandang memiliki sensasi yang lebih (rich sensation) sehingga dapat membuat perjalanan wisata menjadi berkesan (memorable) (Pine \& Gilmore, 2011).

Oleh karena itu, staged activities dapat menjadi bagian dari nilai ekonomi tersebut, sehingga penting untuk dikembangkan dan dikelola.

"at every level in any company, workers need to understand that ini The experience economy every business is a stage, and therefore work is theatre" (Pine \& Gilmore, 2011).

Ketiga, Educational Farm tour, yaitu wisatawan yang lebih mengutamakan activitas tourism first, maka dapat dikembangkan tour mengelilingi lahan pertanian melalui sistem 
subak sekaligus menjelaskan tentang Subak dan melihat langsung beragam aktivitas petani mengerjakan lahannya. Aktivitas lainnya yang dapat dilakukan berupa menikmati hidangan hasil pertanian dan makanan tradisional serta penyediaan souvenir berbasis produk pertanian, seperti beras merah organik hasil kelompok Subak, teh beras meras, biji dan bubuk kopi, dan lain-lain.

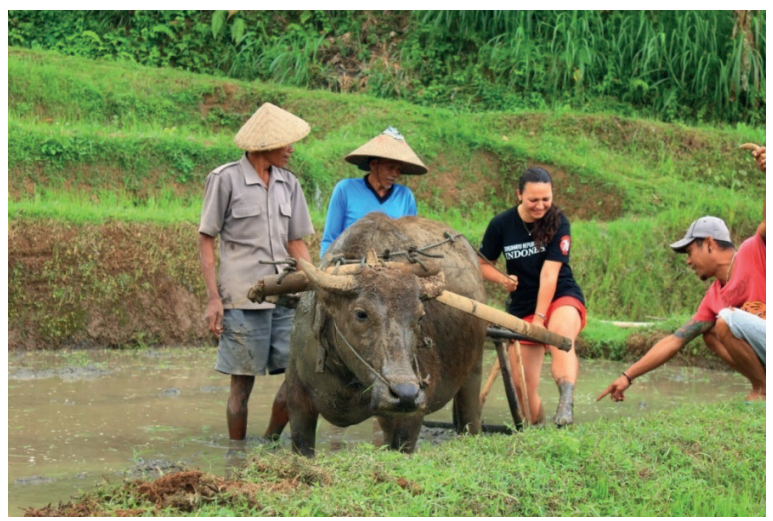

Gambar 6. Belajar mengolah lahan sawah menggunakan kerbau (matekap) sebagai salah satu kegiatan Wisata Edukasi Subak Dokumentasi: Ramaswati Purnawan

\section{Tantangan Wisata Edukasi Subak}

Dari penjelasan di atas, dapat dikatakan bahwa wisata edukasi subak memiliki karakteristik sebagai berikut. Pertama, wisata edukasi ini berbasis alam, khusunya lahan pertanian. Hal ini akan bermanfaat dalam upaya konservasi dan dapat menekan alih fungsi lahan pertanian ke lahan bukan pertanian. Karakteristik kedua adalah adaya pendidikan dan pembelajaran. Pembelajaran termasuk tentang lingkungan alam, termasuk sistem pertanian dan subak di Bali, serta pengetahuan tentang kehidupan sosial budaya masyarakat setempat. Proses pembelajaran ini akan sangat berkesan apabila dilakukan secara terjun langsung (firsthand experience). Ketiga, yaitu wisata edukasi subak dapat menjamin keberlanjutan pembangunan dan selain meningkatkan taraf hidup petani setempat melalui pendapatan tambahan dari aktivitas wisata, wisata edukasi ini dapat memastikan adanya konservasi alam dan budaya setempat, serta mendorong partisipasi masyarakat lokal dalam aktivitas wisata yang dilakukan, maka elemen kunci dalam wisata edukasi subak adalah pariwisata, masyarakat/petani lokal, dan subak.

Akan tetapi, pengembangan wisata edukasi subak ini memiliki beberapa tantangan di antaranya mengubah persepsi bahwa wisata edukasi subak hendaknya tidak dipandang sebagai wisata sawah semata, di mana wisatawan mengunjungi sawah berundak (rice terrace) dan hanya mengagumi keindahan dan mengambil foto. Dengan menyasar mature traveler - mereka yang memiliki keinginan untuk mengetahui budaya setempat - dan karakteristik edukasi tersebut, aktivitas ini diharapkan mampu memberi pemahaman dan pengetahuan tentang nilai dan makna Subak dan budaya melalui paket yang dikemas menarik.

Tantangan lain dari pengembangan wisata edukasi subak adalah tentang sumber daya manusia dan kelembagaan yang akan mengelola aktivitas wisata edukasi subak tersebut. Dengan menggunakan prinsip community-based, idealnya masyarakat setempat dalam hal ini petani Subak, berperan dalam aktivitas wisata dan berinteraksi dengan wisatawan, sehingga aktivitas wisata dapat dirasakan langsung oleh masyarakat setempat. Dengan memperhatikan minimnya latar belakang pendidikan dan pengalaman dalam bidang pariwisata, maka peningkatan kompetensi anggota Subak perlu mendapat perhatian serius. Selain itu, isu kelembagaan juga menjadi esensial karena lembaga ini yang akan berperan dalam pengelolaan sumber daya alam, sumber daya manusia termasuk pembagian prosentasi keuntungan yang proporsional bagi anggota dan masyarakat setempat. Hal ini membutuhkan pelatihan dan pendampingan bagi anggota kelompok Subak tersebut, seperti pelatihan bahasa, guiding serta pendampingan pengelolaan, dan manajemen.

Tantangan ketiga berkaitan dengan promosi yang dilakukan, dengan mengacu kepada prinsip ke-6 dari ICOMOS International Cultural Tourism Charter, maka program promosi seyogyanya dapat melindungi dan meningkatkan karakteristik warisan alam dan budaya, dengan memahami bahwa jenis 
wisata khusus ini termasuk dalam limited industry, target jumlah kunjungan wisatawan disusun secara realistic "...by minimising fluctuations in arrivals and avoiding excessive numbers of visitors at any one time". Sebagaimana dinyatakan oleh Sekretaris Jendral UNWTO, Taleb Rifai.." tourism is dependent on vibrant and well-preserved natural and cultural resources, and so without interest or investment in maintaining them, the sector risks suffering in the long term (UNWTO, 2015). Selain itu, program promosi agar memasukkan informasi mengenai karakteristik destinasi, sehingga proses edukasi dapat dilakukan bagi wisatawan yang datang sehingga mereka secara sadar turut berkontribusi bagi kelestarian alam dan budaya (responsibly inform potential visitors of the specific heritage characteristics of a place or host community, thereby encouraging them to behave appropriately). Program informasi dan edukasi juga penting dilakukan kepada masyarakat lokal agar tumbuh kesadaran akan pentingnya memelihara dan menjaga lahan pertanian, tidak saja demi keberlanjutan perekonomian dan sektor pertanian, tetapi juga untuk kelestarian budaya dan keberlanjutan sektor pariwisata di Bali.

\section{SIMPULAN}

Bali telah memiliki modal penting dalam industri pariwisata, yaitu sumber daya alam yang indah serta warisan budaya yang tetap terpelihara sehingga fokus utama pembangunan ke depan adalah menjamin keberlanjutan sektor yang telah hidup dalam masyarakat, di antaranya sektor pariwisata dan pertanian secara luas, tanpa harus ada dikotomi dan meniadakan salah satu sektor untuk kepentingan sektor lain. Dengan menyasar mature traveler - mereka yang memiliki keinginan untuk mengetahui budaya setempat, baik secara authentic maupun staged, maupun anak sekolah yang sedang melakukan pendidikan atau perjalanan dalam kaitan pembelajaran di negara asalnya, maka wisata edukasi subak merupakan langkah yang dapat dilakukan untuk mewujudkan adanya keberlanjutan (sustainability). Wisata edukasi subak mengandung aspek pelestarian lingkungan alam, sosial budaya dan ekonomi bagi masyarakat setempat. Selain menjaga kelestarian lahan pertanian dan kehidupan sosial budaya masyarakat, wisata edukasi subak ini dapat memberi manfaat ekonomis secara langsung bagi kelompok Subak dan masyarakat lokal setempat. Rekomendasi yang dapat diberikan termasuk upaya informatif dan edukatif kepada masyarakat lokal agar tumbuh kesadaran akan pentingnya memelihara dan menjaga lahan pertanian, tidak saja demi keberlanjutan perekonomian dan sektor pertanian, tetapi juga untuk kelestarian budaya dan keberlanjutan sektor pariwisata di Bali. Untuk memastikan pengembangan paket wisata edukasi subak berjalan dengan baik, maka pelatihan dan pendampingan bagi anggota kelompok subak terkait peningkatan ketrampilan dan kompetensi serta manajemen pengelolaan agar dapat dilakukan secara berkelanjutan dan berkesinambungan, dengan melibatkan berbagai pihak terkait, termasuk pemerintah daerah, akademisi, industri pariwisata, dan yang terpenting adanya partisipasi aktif dari masyarakat setempat.

\section{DAFTAR PUSTAKA}

Badan Pusat Statistik Provinsi Bali. 2017. Provinsi Bali Dalam Angka-Bali Province In Figures 2017. BPS Provinsi Bali. Denpasar

. 2016. Luas Lahan per Kabupaten/Kota Menurut Penggunaannya di Provinsi Bali. BPS Provinsi Bali. Denpasar

ICOMOS, 2002. International Cultural Tourism Charter: Principles and Guidelines for Managing Tourism at Places of Cultural and Heritage Significance, Mexico

OECD. 2015. The Impact of Culture on Tourism. Diakses pada tanggal 19 Agustus 2017. < http://www.oecd.org/>

Provinsi Bali. 2015. Seri Analisis Pembangunan Wilayah Provinsi Bali 2015. Provinsi Bali

Phillip, S., Hunter, C., dan Blackstock, K., 2010. "A typology for defining agritourism", Tourism Management, 31 (2010) 754-758, 
Pine II, B.J. and Gilmore, J.H. 2011. The Experience Economy, Harvard Business Review Press, Boston

Richards, G. 2003. What is Cultural Tourism?. Diakses pada 19 April 2016. < http:/ / www.oecd.org>

Ritchie, B.W., Carr, N., dan Cooper, C., 2003. Managing Educational Tourism. Aspect of Tourism. Channel View Publications, Clevedon.

Sardiana, IK., Purnawan, N.L.R. 2015. "Wisata Ekologi Berbasis Desa Adat di Tenganan Dauh Tukad" dalam Darma Putra, I N (Ed). 2015. Pariwisata Berbasis Masyarakat Model Bali. Program Studi Magister Kajian Pariwisata Universitas Udayana, Denpasar

UNESCO. 2012. Cultural Landscape of Bali Province: the Subak Sistem as a Manifestation of the Tri Hita Karana Philosophy Diakses pada tanggal 19 April 2017. < https://whc.unesco.org/en/ list/1194>
UNWTO. 2015. UNWTO Drives Sustainable Tourism. Interview with United Nations World Tourism Organization (UNWTO) Secretary General, Taleb Rifai. Diakses 19 April 2017. <http:/ / globalislandnews.com>

Windia, W., Pusposutardjo, S., Sutawan, N., Sudira, P dan Supadmo Ari, S., 2005. 'Sistem Irigasi Subak Dengan Landasan Tri Hita Karana (THK) Sebagai teknologi Sepadan Dalam Pertanian Beririgasi' dalam Jurnal SOCA Vol.5, No.3, November 2005. < http://ojs.unud.ac.id/>

Windia, W., Sumiyati, Sedana, G., 2015. 'Aspek Ritual pada Sistem Irigasi Subak sebagai Warisan Budaya Dunia', Jurnal Kajian Bali, Vol. 05., No.01., April 2015

Wirawan, A.A.B. 2011. 'SWECAPURA : Dari Nama Keraton menjadi Nama Subak di Desa Gelgel, Abad ke-14 dan Abad ke-20 dalam Ebisawa, T (ed) The Subak Gede Swcapura and the Gelgel Kingdom in Bali, Tokyo, Jepang 